\title{
Love at First Sight
}

\author{
James A. Grant-Jacob * \\ Faculty of Physical Sciences and Engineering, University of Southampton, Southampton, UK
}

Keywords: interpersonal attraction, love, emotion, interpersonal relationships, perception

Evolved traits such as intuitive skills have allowed individuals to quickly evaluate a suitable sexual partner in about $100 \mathrm{~ms}$ (Olson and Marshuetz, 2005; Willis and Todorov, 2006; Todorov, 2008). Having determined that someone is attractive at first sight, an individual may become emotionally attached to that person and communicate their affection via a copulatory gaze, in which the individual gazes into the other person's eyes for many seconds (Fisher, 1992). In this opinion piece, I discuss why an individual can become attracted to and emotionally attached to another person in an instant at first sight and I propose how such feelings may be requited and thus how love at first sight between two people can occur if the receiver of such attraction has similar attributes to the individual.

A person's perceived attractiveness can vary depending on the individual who is perceiving their attractiveness. Studies on attraction have shown that people are strongly sexually attracted to lookalikes in physical appearance (Folkes, 1982; Alvarez and Bolívar, 2004; Malin, 2004), with researchers having found that subjects rated pictures of faces morphed with their own face as being more attractive (Penton-Voak et al., 1999). In work by Zaidel et al. (2003), subjects found that those faces that were more attractive, were also more trustworthy. An individual's personality and trustworthiness can be perceived in the subtle nonverbal behavioral information of such primary facial features as the eyes (Argyle, 1988; Little and Perrett, 2007) and we can perceive from someone's face whether they are happy, sad, well or ill (Rhodes and Zebrowitz, 2002; Ekman and Friesen, 2003). We can sometimes even perceive sexual orientation (Rule et al., 2009) and perhaps intelligence (Zebrowitz et al., 2002; Kanazawa, 2011). As such, I believe it is our ability to perceive another individual's personality that can allow us to be attracted to someone before we have even spoken to them.

Researchers have shown that interpersonal attraction is positively correlated to personality similarity, with positive people preferring to be with other positive people (Byrne and Griffitt, 1973), and individuals are also attracted to others who are similar in culture, economic status and socialness (Byrne et al., 1966; Berscheid et al., 1971; Buss and Barnes, 1986). As such, in my opinion, since an individual is generally attracted to someone who they believe they can trust and perhaps be in a happy relationship with, and usually, since that person is someone who has a personality similar to their own, those people who look similar to the individual are perceived as having a similar personality to that individual, and are therefore perceived to be more attractive. In addition, because individuals may inherit similar facial features to their parents, those who look like the individual may also be seen as trustworthy, since they may be a reminder of trusting faces from childhood (Perrett, 2010). Such belief in a lookalike being trustworthy and suitable relationship material is not unfounded in the literature, as couples who have similar physical attributes have shown to demonstrate strong relationship commitment (Murstein, 1972) and relationship stability (Kurdek and Schnopp-Wyatt, 1997). Although, the apparent superficial manner of falling in love at first sight could mean an individual may become attached to someone they have nothing in common with, and thus potentially be involved in a relationship that may not last long, the positive impact of the first impression can compensate the superficial manner of attraction at first sight (Sunnafrank and Ramirez, 2004; Barelds and Barelds-Dijkstra, 2007), and as discussed by Tops et al. (2014), the positive initial impact can become replaced with familiarity and predictability of the partner, which can lead to a potentially long-term attraction.

The attraction of the individual to another person can be conveyed by their eyes, i.e., via copulatory gaze, such that the more an individual likes that person, the longer they want to gaze 
into their eyes in order to express the strength of our feelings (Rubin, 1970). Therefore, after having looked into the other person's eyes to determine if they are attractive, the individual may continue to gaze into the other person's eyes for many seconds. By an individual conveying their feelings of attraction to the person they are attracted to, the receiver of such attraction may be attracted back to the individual, not only because they are being appraised as being a suitable partner, and as suggested by Myers (2012), there is essentially less energy needed for them to claim a mate, but in my view, because the individual may attracted to the receiver because the receiver is a look-a-like, the receiver may in turn perceive the individual as having similar attributes and thus perceived as having a suitable personality too. As such, the receiver may gaze back into the individuals' eyes to convey that they like them. The gazing back may reinforce the individual's belief that the receiver of their attraction is suitable, and as both individuals gaze into each other's eyes, they perhaps realize that they are both attracted to each other, and so an immediate unspoken emotional union is potentially formed in which both

\section{REFERENCES}

Alvarez, L., and Bolívar, U. S. (2004). Narcissism guides mate selection: humans mate assortatively, as revealed by facial resemblance, following an algorithm of "Self Seeking Like". Evol. Psychol. 2, 177-194. doi: $10.1177 / 1474704904002001223$

Argyle, M. (1988). Bodily Communication, 2nd Edn. London: Methuen.

Barelds, D. P. H., and Barelds-Dijkstra, P. (2007). Love at first sight or friends first? Ties among partner personality trait similarity, relationship onset, relationship quality, and love. J. Soc. Pers. Relat. 24, 479-496. doi: $10.1177 / 0265407507079235$

Berscheid, E., Dion, K., Walster, E., and Walster, G. W. (1971). Physical attractiveness and dating choice: a test of the matching hypothesis. J. Exp. Soc. Psychol. 7, 173-189. doi: 10.1016/0022-1031(71)90065-5

Buss, D. M., and Barnes, M. (1986). Preferences in human mate selection. J. Pers. Soc. Psychol. 50, 559-570. doi: 10.1037/0022-3514.50.3.559

Byrne, D., Gerald, L. J. C., and Worchel, P. (1966). Effect of economic similaritydissimilarity on interpersonal attraction. J. Pers. Soc. Psychol. 4, 220-224. doi: 10.1037/h0023559

Byrne, D., and Griffitt, W. (1973). Interpersonal attraction. Annu. Rev. Psychol. 24, 317-336. doi: 10.1146/annurev.ps.24.020173.001533

Ekman, P., and Friesen, W. V. (2003). Unmasking the Face: A Guide to Recognizing Emotions from Facial Clues. Cambridge: Malor Books.

Fisher, H. E. (1992). Anatomy of Love: The Natural History of Monogamy, Adultery, and Divorce. New York, NY: Norton.

Folkes, V. S. (1982). Forming Relationships and the Matching Hypothesis. Personal. Soc. Psychol. Bull. 8, 631-636. doi: 10.1177/0146167282084005

Kanazawa, S. (2011). Intelligence Intelligence and physical attractiveness. Intelligence 39, 7-14. doi: 10.1016/j.intell.2010.11.003

Kurdek, L. A., and Schnopp-Wyatt, D. (1997). Predicting relationship commitment and relationship stability from both partners' relationship values: evidence from heterosexual dating couples. Personal. Soc. Psychol. Bull. 23, 1111-1119. doi: 10.1177/01461672972310011

Little, A. C., and Perrett, D. I. (2007). Using composite images to assess accuracy in personality attribution to faces. Br. J. Psychol. 98, 111-126. doi: 10.1348/000712606X109648

Malin, S. (2004). Love at First Sight. New York, NY: DK Publishing Inc.

Murstein, B. I. (1972). Physical attractiveness and marital choice. J. Pers. Soc. Psychol. 22, 8-12. doi: 10.1037/h0032394

Myers, D. G. (2012). Social Psychology. New York, NY: McGraw-Hill Higher Education.

Olson, I. R., and Marshuetz, C. (2005). Facial attractiveness is appraised in a glance. Emotion 5, 498-502. doi: 10.1037/1528-3542.5.4.498 individuals become emotionally attached to each other, and love at first sight occurs between two people at the same time.

A comparative study of individuals in relationships formed from reciprocated love at first sight, which involves discussions of the individuals' initial attraction, as well as the individuals' perceived personalities before and during the relationship, will hopefully explore the ideas expressed in this work as well as aid in our understanding of the prevalence and mechanics of love at first sight.

\section{AUTHOR CONTRIBUTIONS}

The author confirms being the sole contributor of this work and approved it for publication.

\section{ACKNOWLEDGMENTS}

I am thankful for assistance from the editor Jennifer Michelle Windt and the reviewer during the review process.

Penton-Voak, I. S., Perrett, D. I., and Peirce, J. W. (1999). Computer graphic studies of the role of facial similarity in judgements of attractiveness. Curr. Psychol. 18, 104-117.

Perrett, D. I. (2010). In Your Face: The New Science of Human Attraction. London: Palgrave Macmillan.

Rhodes, G., and Zebrowitz, L. A. (2002). Facial Attractiveness: Evolutionary, Cognitive, and Social Perspectives. Westport: Ablex.

Rubin, Z. (1970). Measurement of romantic love. J. Pers. Soc. Psychol. 16, 265-273.

Rule, N. O., Ambady, N., and Hallett, K. C. (2009). Female sexual orientation is perceived accurately, rapidly, and automatically from the face and its features. J. Exp. Soc. Psychol. 45, 1245-1251. doi: 10.1016/j.jesp.2009. 07.010

Sunnafrank, M., and Ramirez, A. (2004). At first sight: persistent relational effects of get-acquainted conversations. J. Soc. Pers. Relationships 21, 361-379. doi: $10.1177 / 0265407504042837$

Todorov, A. (2008). Evaluating faces on trustworthiness: an extension of systems for recognition of emotions signaling approach/avoidance behaviors. Ann. N.Y. Acad. Sci. 1124, 208-224. doi: 10.1196/annals.1440.012

Tops, M., Koole, S. L., Ijzerman, H., and Buisman-pijlman, F. T. A. (2014). Pharmacology, Biochemistry and Behavior Why social attachment and oxytocin protect against addiction and stress: insights from the dynamics between ventral and dorsal corticostriatal systems. Pharmacol. Biochem. Behav. 119, 39-48. doi: 10.1016/j.pbb.2013.07.015

Willis, J., and Todorov, A. (2006). First impressions making up your mind after a 100-ms exposure to a face. Psychol. Sci. 17, 592-598. doi: 10.1111/j.14679280.2006.01750.x

Zaidel, D. W., Bava, S., and Reis, V. A. (2003). Relationship between facial asymmetry and judging trustworthiness in faces. Laterality 8, 225-232. doi: 10.1080/13576500244000120

Zebrowitz, L. A., Hall, J. A., Murphy, N. A., and Rhodes, G. (2002). Looking smart and looking good: facial cues to intelligence and their origins. Personal. Soc. Psychol. Bull. 28, 238-249. doi: 10.1177/0146167202282009

Conflict of Interest Statement: The author declares that the research was conducted in the absence of any commercial or financial relationships that could be construed as a potential conflict of interest.

Copyright (c) 2016 Grant-Jacob. This is an open-access article distributed under the terms of the Creative Commons Attribution License (CC BY). The use, distribution or reproduction in other forums is permitted, provided the original author (s) or licensor are credited and that the original publication in this journal is cited, in accordance with accepted academic practice. No use, distribution or reproduction is permitted which does not comply with these terms. 